(C) The Author(s) 2016. This is an Open Access article, distributed under the terms of the Creative Commons Attribution licence (http://creativecommons. org/licenses/by/4.0/), which permits unrestricted re-use, distribution, and reproduction in any medium, provided the original work is properly cited.

\title{
Air temperature variability in a high-elevation Himalayan catchment
}

\author{
Martin HEYNEN, ${ }^{1}$ Evan MILES, ${ }^{2}$ Silvan RAGETTLI, ${ }^{1}$ Pascal BURI, ${ }^{1}$ \\ Walter W. IMMERZEEL, ${ }^{3}$ Francesca PELLICCIOTTII ${ }^{1,4}$ \\ ${ }^{1}$ Institute of Environmental Engineering, ETH Zürich, Zürich, Switzerland \\ ${ }^{2}$ Scott Polar Research Institute, University of Cambridge, Cambridge, UK \\ ${ }^{3}$ Department of Physical Geography, Utrecht University, Utrecht, The Netherlands \\ ${ }^{4}$ Department of Geography, Northumbria University, Newcastle upon Tyne, UK \\ Correspondence: Martin Heynen <martinheynen@gmx.net>
}

\begin{abstract}
Air temperature is a key control of processes affecting snow and glaciers in high-elevation catchments, including melt, snowfall and sublimation. It is therefore a key input variable to models of land-surface-atmosphere interaction. Despite this importance, its spatial variability is poorly understood and simple assumptions are made to extrapolate it from point observations to the catchment scale. We use a dataset of 2.75 years of air temperature measurements (from May 2012 to November 2014) at a network of up to 27 locations in the Langtang River, Nepal, catchment to investigate air temperature seasonality and consistency between years. We use observations from high elevations and from the easternmost section of the basin to corroborate previous findings of shallow lapse rates. Seasonal variability is strong, with shallowest lapse rates during the monsoon season. Diurnal variability is also strong and should be taken into account since processes such as melt have a pronounced diurnal variability. Use of seasonal lapse rates seems crucial for glacio-hydrological modelling, but seasonal lapse rates seem stable over the 2-3 years investigated. Lateral variability at transects across valley is high and dominated by aspect, with south-facing sites being warmer than north-facing sites and deviations from the fitted lapse rates of up to several degrees. Local factors (e.g. topographic shading) can reduce or enhance this effect. The interplay of radiation, aspect and elevation should be further investigated with high-elevation transects.
\end{abstract}

KEYWORDS: debris-covered glaciers, glacier mass balance, glacier meteorology, glaciological instruments and methods, mountain glaciers, surface melt

\section{INTRODUCTION}

Mountain air temperature is considerably different from that of the free atmosphere. It is affected by surface processes that can be locally relevant (Minder and others, 2010), and important controls include longwave radiation emitted by the terrain, exchange of heat due to turbulent flows and the effect of radiative fluxes incident on mountain slopes. In complex topography, airflows, including katabatic flows, and atmospheric circulation develop that can affect the local meteorology considerably. In valley bottoms, pooling of cold air can occur (Lundquist and others, 2008; Minder and others, 2010) and at high elevations snow and glaciers moderate near-surface air temperature (Petersen and Pellicciotti, 2011; Petersen and others, 2013; Ayala and others, 2015). Despite this, air temperature is often assumed to vary as free atmosphere temperature, and lapse rates that have been suggested to be typical of the free atmosphere have been widely used to obtain distributed input temperature to snow models, glacier melt and mass-balance models and hydrological models. Thus, temperature is often assumed to decrease linearly with elevation according to spatially and temporally constant lapse rates (LRs) that are commonly taken to be between 0.0060 and $0.0065^{\circ} \mathrm{C} \mathrm{m}^{-1}$, with little or no justification for these values (Minder and others, 2010). Several authors, however, have pointed to the fact that terrain and surface processes are important in determining surface temperatures and that local variability can be high, especially in mountainous terrain (Blandford and others, 2008; Minder and others, 2010; Thayyen and Dimri, 2014), that LRs are not constant in time (Petersen and Pellicciotti, 2011; Ayala and others, 2015) and that the assumption of a uniform LR leads to large errors in model simulations (Minder and others, 2010; Petersen and Pellicciotti, 2011; Immerzeel and others, 2014). While previous studies have investigated large-scale LR variations and controls for mid-elevation sites (e.g. Rolland, 2002; Marshall and others, 2007), a recent focus has been on very high elevations and glacierized sites (e.g. Gardner and others, 2009; Petersen and Pellicciotti, 2011; Ayala and others, 2015).

The presence of snow and glaciers is well known to alter the surface boundary layer and the temperature regime (Greuell and Böhm, 1998; Ayala and others, 2015). Even when glacier-covered areas are discarded, high mountain catchments show complex patterns of airflow that affect temperature, precipitation and wind variability. Orographic effects are important, and in the central Himalaya the monsoon, bringing a considerable amount of moisture to the region, establishes a well-defined seasonality and additionally affects air temperature variability. Very few studies of air temperature variability have been conducted in the Himalaya and High Mountain Asia in general, because of inaccessibility, difficulties in data collection and the costs of deploying a network of distributed sensors (Fujita and 


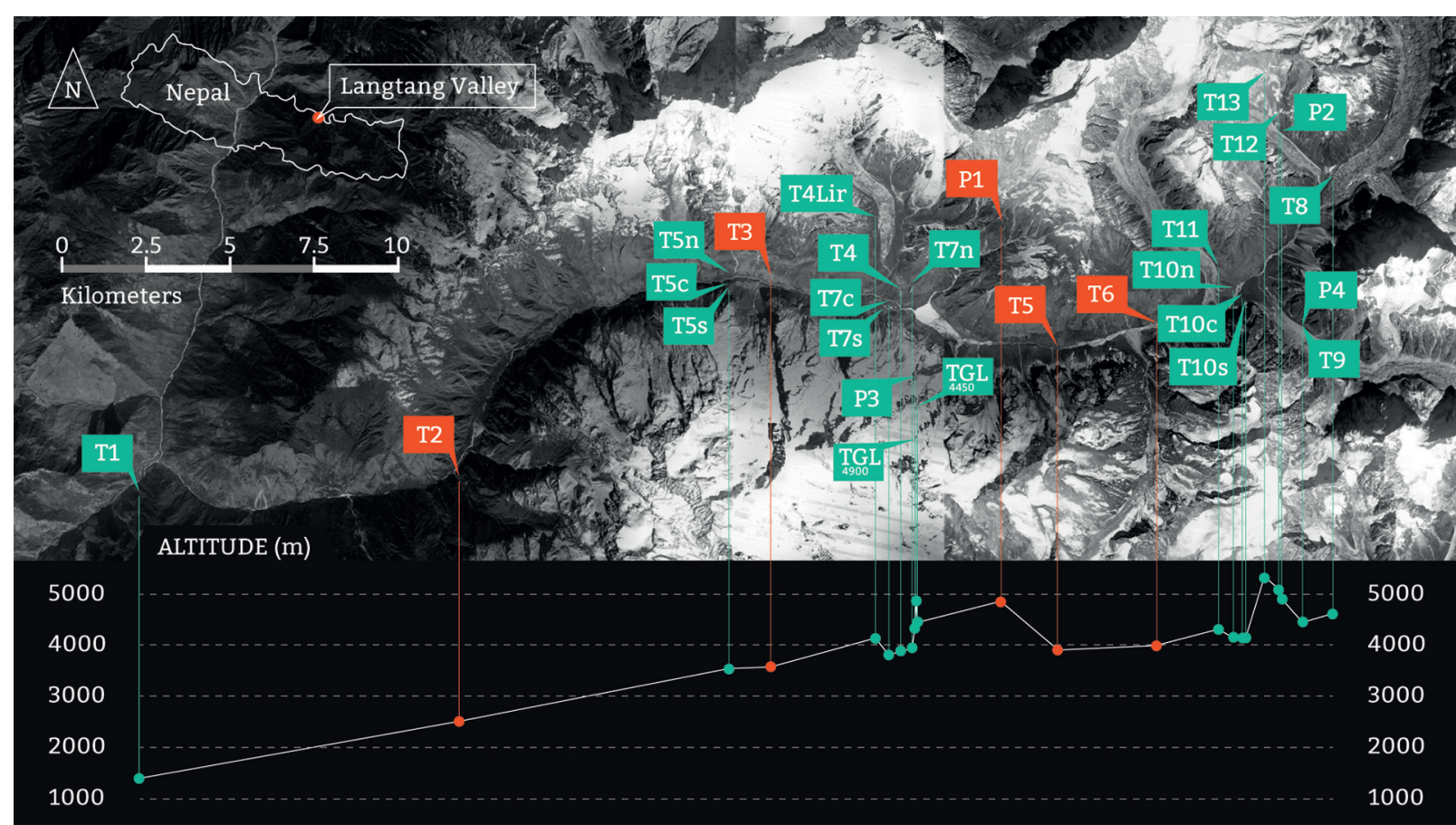

Fig. 1. Map of the Langtang River catchment with the location of all the temperature sensors used in this study ( $T$-loggers, marked as TXX, and pluviometers, marked as PXX), and their respective altitudes (shown in the bottom panel). The instruments of the lower-valley subset are indicated in red, similar to the set-up used by Immerzeel and others (2014) in 2012/13, and the new instruments are indicated in green. The map in the upper left corner indicates the location of the catchment in Nepal.

Sakai, 2000; Kattel and others, 2012; Immerzeel and others, 2014; Thayyen and Dimri, 2014). No study has looked at the consistency of the observed spatial and seasonal patterns over several years and at the interannual variability of LRs at the catchment scale and for high-elevation headwater areas, despite the fact that this variability is considerable in other mountain regions (Minder and others, 2010).

In this study we build on the work by Immerzeel and others (2014), who looked at temperature lapse rates in the upper Langtang River catchment of central Nepal for 1 year, and extend their analysis with two additional years of observation and several higher-elevation sites. Immerzeel and others (2014) analysed temperature data from six temperature data-loggers ( $T$-loggers) installed between the outlet of the valley (1406 ma.s.l.; T1 in Fig. 1) and a midvalley location (3981 ma.s.I.; T6 in Fig. 1), between May 2012 and May 2013, together with data at one highelevation site (4831 ma.s.l.; P1 in Fig. 1). They calculated seasonal LRs and found a high correlation between temperature and elevation, but LRs were shallower than the environmental lapse rate $\left(0.0065^{\circ} \mathrm{C} \mathrm{m}^{-1}\right)$ and varied strongly on a seasonal and diurnal basis. The network used by Immerzeel and others (2014) ended in the middle of the valley, so in the present study additional sensors were installed further up in the valley to cover its easternmost reaches, and several were installed across valley and at higher elevations to provide a more complete picture of air temperature variability in the catchment.

The main aims of our paper are: (1) to test if the findings of Immerzeel and others (2014) remain valid when we include air temperature records from higher-elevation sites and sites deeper into the valley, where it is known that precipitation decreases considerably (Ragettli and others, 2015); and (2) to investigate if the observed seasonal LRs are stable over multiple years. We investigate the seasonal and diurnal variability in LRs and analyse the local variability at transects of similar elevation across the main valley direction. In this paper we do not consider on-glacier observations of temperature, which were made on a small portion of the debris-covered tongue of Lirung Glacier. These measurements are analysed in a companion publication (Steiner and Pellicciotti, 2016) to investigate the effect of debris thickness and local topography on the small-scale temperature variability over debris-covered glaciers.

\section{STUDY SITE AND DATA}

\subsection{Field site}

Temperature measurements were conducted in the upper Langtang River catchment in the central Himalaya, Nepal (Fig. 1), a catchment that has been uniquely instrumented over the past few years thanks to joint efforts by ETH Zürich, Utrecht University, the University of Cambridge and ICIMOD (International Centre for Integrated Mountain Development, Kathmandu, Nepal). The catchment's glaciers and hydrology have been extensively studied (e.g. Ragettli and others, 2015; Steiner and others, 2015; Buri and others, 2016; Miles and others, 2016; Steiner and Pellicciotti, 2016) to understand the catchment response to a changing climate, and this study is part of that large effort.

The Langtang River is part of the Trishuli River system in the central Himalaya. Its drainage area upstream of Syafru Besi is $585 \mathrm{~km}^{2}$, of which $155 \mathrm{~km}^{2}$ is glacierized, with most glacier area below $5200 \mathrm{~m}$ a.s.l. covered by rock debris. The elevation ranges from $1406 \mathrm{ma.s.l}$. in Syafru Besi to $7234 \mathrm{~m}$ a.s.l. at the summit of Langtang Lirung. The climate is dominated by monsoon circulation, with predominant easterly winds in the summer, and westerly winds from October to May (Immerzeel and others, 2014). 


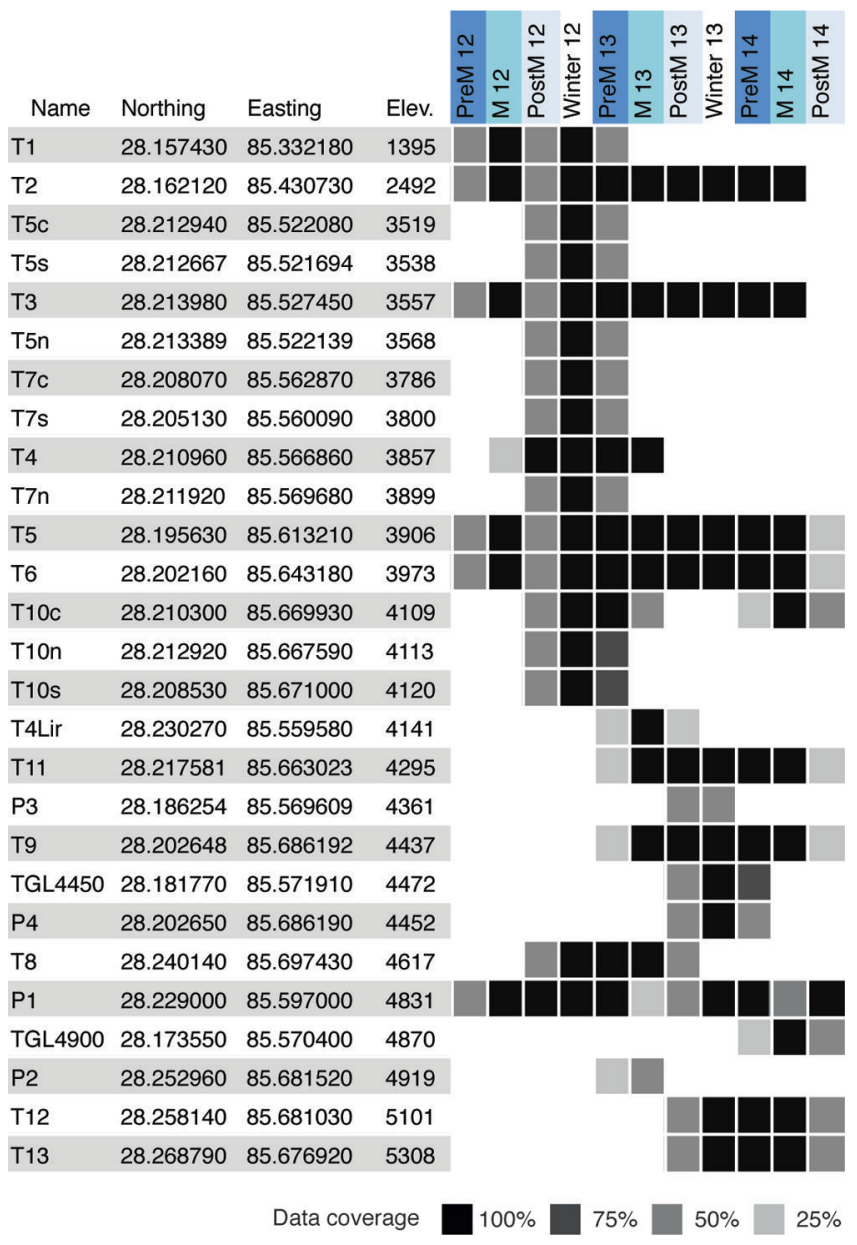

Fig. 2. Names, coordinates and elevations of the temperature sensors installed in the Langtang River catchment. Elevation is in $m$ a.s.l. Data availability at each site is indicated for each season by shading. PreM indicates the pre-monsoon season, $M$ the monsoon season, PostM the post-monsoon season and Winter the winter season, as defined in Table 1. The last two numbers indicate the year.

\subsection{Data}

All temperature measurements considered in this work are from sites located off-glacier. Air temperature was recorded at several $T$-loggers (indicated by TXX as in Immerzeel and others, 2014) and high-precision Ott pluviometers (PXX). The locations and altitudes of the temperature loggers and pluviometers are shown in Figures 1 and 2. The temperature loggers are Onset models HOBO TidbiT v2 UTBI-001 and HOBO U23-001 Pro v2, and were set to record air temperature at 5,10 or $15 \mathrm{~min}$ intervals. The units were housed in PVC cylinders allowing natural ventilation through channelization of airflow and covered with an aluminium foil to shield the sensors from direct incoming shortwave radiation. The cylinders were mounted on a metal pole at a distance of $2 \mathrm{~m}$ above the surface. They have an accuracy of $0.2{ }^{\circ} \mathrm{C}$ in the range $0-50^{\circ} \mathrm{C}$ (Petersen and Pellicciotti, 2011). Additionally, temperature observations were made at four total pluviometers equipped with a rugged Campbell temperature probe 109-L which measures air temperatures from -50 to $+70^{\circ} \mathrm{C}$. The sensor was placed in an unaspirated radiation shield (Campbell MET20) to avoid direct radiation, and temperature was logged at a 15 min interval.
Table 1. Definition of seasons used in this study

\begin{tabular}{lccc}
\hline Season & Short name & Start & End \\
\hline Pre-monsoon & PreM & 1 Mar & 14 Jun \\
Monsoon & $M$ & 15 Jun & 30 Sep \\
Post-monsoon & PostM & 1 Oct & 30 Nov \\
Winter & Winter & 1 Dec & 28 Feb \\
\hline
\end{tabular}

\section{METHODS}

Temperature measurements started on 1 May 2012 and ended on 30 November 2014. Figure 2 shows the data coverage at each location and for each season within this measurement period. At several locations, sensors failed for some periods because of the extreme conditions, battery issues and damage. All measurements were averaged to hourly values. For every year we calculated the seasonal mean temperature for the four seasons pre-monsoon, monsoon, post-monsoon and winter as defined in Table 1. To calculate the daily temperature cycle, hourly means for each hour of the day per season and per year were calculated. These mean hourly temperature values were used to calculate diurnal LR variability. Air temperature is normally assumed to decrease linearly with elevation (Marshall and Sharp, 2008) under well-mixed atmospheric conditions (Lundquist and others, 2008), so that a LR can be defined as (Petersen and Pellicciotti, 2011)

$$
\mathrm{LR}=\frac{T_{1}-T_{2}}{z_{1}-z_{2}}=\frac{\mathrm{d} T}{\mathrm{~d} z}
$$

where $T_{1}$ and $T_{2}$ are the air temperatures of the higher and lower point, and $z_{1}$ and $z_{2}$ are their elevations (m). For calculation of LRs, however, it has been suggested that multiple measurements should be used, as this allows calculation of the strength of the relationship between air temperature and elevation (Marshall and others, 2007; Petersen and Pellicciotti, 2011; Kattel and others, 2012). We thus calculate the whole-valley LRs from regression of all mean temperature values, and the measure of the strength of the altitudinal dependence is provided by the correlation coefficients of the linear regression. A more negative (steep) lapse rate indicates that temperature decreases rapidly with elevation, whereas the decrease is slower for a less negative (shallow) lapse rate (Pepin and Losleben, 2002; Petersen and Pellicciotti, 2011).

We analyse the dataset with three main aims in mind: (1) investigate seasonal variability in LRs, following the findings of Immerzeel and others (2014); (2) investigate the local variability in air temperature, using several new sites off the main valley axis; and (3) examine in particular whether seasonal LRs are stable over 3 years. To demonstrate the importance of accurate LRs we calculate the elevation of the $0^{\circ} \mathrm{C}$ line corresponding to the calculated LRs and analyse differences obtained in this way.

\subsection{Interannual variability}

To analyse the interannual variability of LRs, we calculate seasonal and hourly LRs with the stations that cover the entire measurement period (T2, T3, T5, T6 and P1; Figs 1 and 2). This dataset, indicated in red in Figure 1, is very similar to that used in Immerzeel and others (2014). The only location included in Immerzeel and others (2014) but 
missing from this analysis is T4, for which data coverage was insufficient (Fig. 2).

For every year we compute the seasonal LRs as well as the LR diurnal cycle and the corresponding correlation coefficients $R^{2}$. We also calculate daily LRs and present the basic statistics (mean and standard deviation) for each of the seasons considered. We then compare these LRs with those obtained by considering all available locations for each season and year. In this way, comparability is not entirely justified, because LRs are obtained using different datasets. However, this approach allows us to establish whether a clear LR signal or pattern exists independently of the number of sensors used to detect it.

\subsection{Intra-seasonal variability and lapse rate stability over monsoon}

We plot the daily LRs over 1 year together with the strength of their regression $\left(R^{2}\right)$ for both the valley dataset and for all sensors available. This demonstrates the variability between years and seasons, and allows further exploration of the intra-seasonal variability in LRs, a topic not analysed in Immerzeel and others (2014).

Previous studies have suggested that the monsoon lowers the LR (Kattel and others, 2012; Immerzeel and others, 2014; Thayyen and Dimri, 2014). In the central Himalaya generally and in the Langtang catchment specifically, the monsoon is the season during which most of the melt occurs and at the same time most of the precipitation falls, the phase of which is controlled by temperature. It thus seems important to understand air temperature LRs during this season in particular. Three monsoon seasons are available with extensive data coverage: monsoon 2012 (for which seven records of observations are available), monsoon 2013 (12 records) and monsoon 2014 (10 records) (Fig. 2). To verify that $L R s$ are stable across the three seasons we therefore compare the seasonal mean LRs calculated with all available $T$-loggers during each season, thus inferring also how strongly dependent on location and number of recording sites the values obtained are.

\subsection{Local variability}

During post-monsoon 2012, winter 2012/13 and premonsoon 2013, three sensor transects were installed across the valley to inspect local effects (Fig. 1). Each transect included three $T$-loggers: one in the northern part of the valley (indicated by suffix $\mathrm{n}$ ) one in the center, usually along the main valley bottom (suffix c), and one on the southern flank of the valley (suffix s). The transects cover the lower (T5n, T5c, T5s), middle (T7n, T7c, T7s) and upper (T10n, T10c, T10s) portions of the upper Langtang valley, where cryospheric processes are most prevalent.

To assess local variability, we calculated the seasonal mean LRs with all available $T$-loggers during these three seasons and checked if observations at the transects followed the same pattern given by the main LR regression line.

We also model solar radiation to understand the differences in observed air temperature relative to the main valley LR. Potential incoming shortwave radiation at each site was obtained by running a solar radiation model described in detail in Pellicciotti and others (2011) and Ragettli and others (2015). The model calculates potential clear-sky global irradiance with a non-parametric model based on Iqbal (1983) accounting for the position of the sun relative to every gridcell at each time step and for transmissivity through the atmosphere. A vectorial algebra approach is used for the interaction between the solar beam and terrain geometry. The model was applied at a grid resolution of $30 \mathrm{~m}$ using the Advanced Spaceborne Thermal Emission and Reflection Radiometer (ASTER) Global Digital Elevation Model (GDEM) (available on http://gdem.ersdac. jspacesystems.or.jp/).

\subsection{Impact on the elevation of the $0^{\circ} \mathrm{C}$ line}

Differences in LRs are important not only per se but also for the impact they have on calculations of melt, snowfall, snow sublimation and other processes typical of high-elevation catchments. Both melt and the phase of the precipitation are controlled by thresholds that define the onset of melt and whether precipitation is liquid or solid. In general, both processes are assumed to occur above a threshold temperature near $0^{\circ} \mathrm{C}$ (e.g. Ragettli and others, 2015) so that the elevation of the isotherm prescribed when using different lapse rates seems an important indication of differences to expect in model simulations of the catchment hydrology. We extrapolate air temperature from an automatic weather station adjacent to T4 (see Immerzeel and others, 2014; Ragettli and others, 2015) (Fig. 1) using a constant annual LR or the seasonally derived LRs to calculate the elevation of the $0^{\circ} \mathrm{C}$ isotherm. Accordingly, we test two LR configurations: (1) a constant annual LR (for every year); and (2) a constant seasonal LR (for every season).

\section{RESULTS AND DISCUSSION}

\subsection{Interannual seasonality}

Figure 3 shows the mean LRs for the four seasons for each year for which enough data were available. LRs are calculated at the five locations listed in Section 3.1 and shown in red in Figure 1. Three successive years (2012-14) of data are available for all seasons except winter, for which only 2012 and 2013 are available. Table 2 lists the mean and standard deviation of the daily LRs for all seasons and years for the same configuration (i.e. main valley subset, indicated as 'Sensor subset' in the table). LRs are calculated from regression of the observations for each day with regression $p<0.1$ to remove days where a single $L R$ is an inadequate description of the temperature profile, or where inadequate observations were available (of 944 measurements, this affected 6 days for the 'Full set' and 62 days for the 'Sensor subset').

LRs are consistent over the three years in both their mean values (Fig. 3a) and daily cycle (Fig. 3b). ) It is also evident that LRs are different between the seasons, with the shallowest LRs in monsoon and the steepest in pre-monsoon for all years (Fig. 3a; Table 2). This agrees with previous findings by Immerzeel and others (2014) for the same catchment for 2012, and with results of Thayyen and Dimri (2014), who also obtained shallowest LRs in monsoon for the lower reaches of the Dingad catchment, Garhwal Himalaya, India, a phenomenon they termed monsoon lowering. However, the lowering was not observed for the upper sections (covered by snow and glaciers) of the catchment. Kattel and others (2012), examining LRs over all of Nepal for a network of 56 stations, also found a clear annual cycle in temperature lapse rates, with the steepest value in pre-monsoon and the shallowest in monsoon. Previous studies in other regions of the world have suggested that LRs are shallower in humid or cooler 

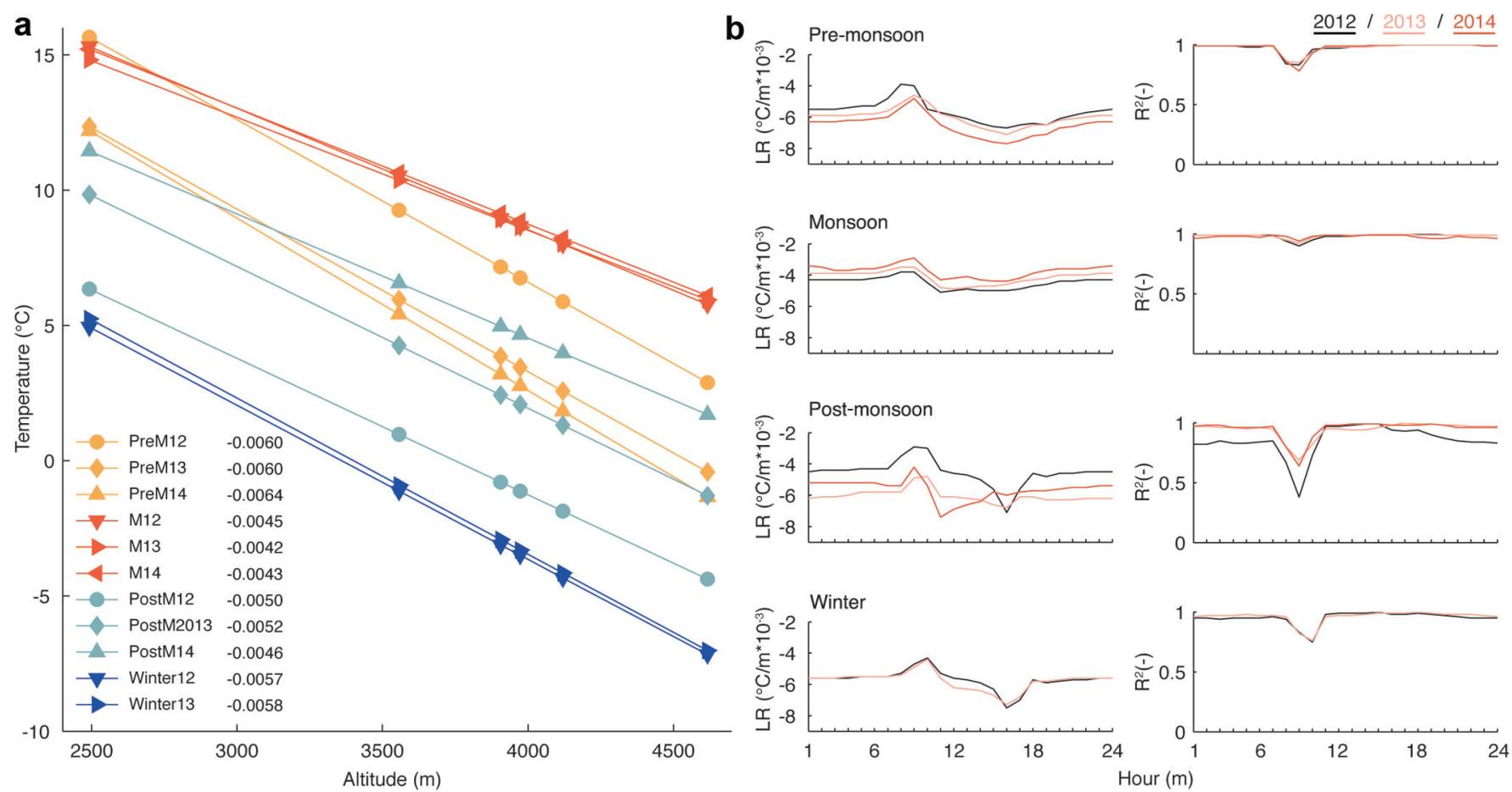

Fig. 3. (a) Mean seasonal LRs at the five locations listed in Section 3.1 and shown in red in Figure 1 for all seasons with sufficient data coverage. Names of seasons are as listed in Table 1. The corresponding LRs $\left({ }^{\circ} \mathrm{C} \mathrm{m}^{-1}\right)$ are calculated as the seasonal mean of daily LRs. (b) Diurnal cycle of the seasonal LRs and correlation coefficient, $R^{2}$, for each season. No data are available for winter 2014.

atmospheric conditions, and steeper in drier or warmer conditions (Pepin, 2001; Blandford and others, 2008; Gardner and others, 2009; Minder and others, 2010). The seasonal pattern we obtain is in good agreement with these findings for different regions and with those of Kattel and others (2012) for the same region but for lower elevations (their highest station was at $3920 \mathrm{~m}$ a.s.l.).

The shallow monsoon LRs can be explained by the latent heat release in the free atmosphere at high elevations associated with the monsoon precipitation (Kattel and others, 2012). The air over high elevations will be warmed by latent heat release associated with water vapour condensation, thereby reducing the lapse rate. The transfer of latent heat depends on the moisture content in the atmosphere (Marshall and others, 2007). In response to the heavy monsoon rainfalls, surface temperatures decrease and moist adiabatic processes prevail. The radiative effect of clouds also plays a role during monsoon by reducing the variability in temperature and LRs, as confirmed by the standard deviations in this season, which are the lowest of all seasons (Table 2). Cloudy skies and moist conditions reduce incoming solar radiation during the day and increase the net longwave radiation at the surface at night. As a result, the minimum temperature at night is higher, daytime LRs become shallower and night-time LRs become steeper enhanced, minimizing the range of the diurnal cycle.

Kattel and others (2012) obtained a second very shallow LR in winter that is not evident in our record, where winter LRs are of similar magnitude to those of the post-monsoon, and intermediate between the post-monsoon and premonsoon values (Table 2). This difference is potentially related to the high elevation of our sites (our highest site is at 5300 ma.s.l. in contrast to the 3920 ma.s.l. of Kattel and others, 2012), which are affected greatly by snow cover in winter. A similar effect was found by Thayyen and Dimri (2014), who observed a different behaviour for the upper parts of the catchment covered by snow and glaciers.

Table 2. Summary of the basic seasonal LR statistics for both the 'Sensor subset' (the five locations shown in red in Fig. 1) and the 'Full sensor set' (all available sensors for that specific season and year). PreM indicates the pre-monsoon, $\mathrm{M}$ the monsoon and Post $\mathrm{M}$ the post-monsoon season. $\mu$ and $\sigma$ are the mean and standard deviation calculated from daily LRs. Units are ${ }^{\circ} \mathrm{C} \mathrm{m}^{-1}$

2012

\section{Sensor subset}

Season

$\mu$
Full sensor set
2013

Sensor subset
Full sensor set
2014

Sensor subset Full sensor set

\begin{tabular}{lllllllllllll}
\hline PreM & -0.0060 & 0.0004 & -0.0063 & 0.0004 & -0.0060 & 0.0009 & -0.0060 & 0.0008 & -0.0064 & 0.0007 & -0.0063 & 0.0008 \\
M & -0.0045 & 0.0004 & -0.0046 & 0.0005 & -0.0042 & 0.0005 & -0.0044 & 0.0004 & -0.0043 & 0.0006 & -0.0048 & 0.0003 \\
PostM & -0.0050 & 0.0009 & -0.0052 & 0.0006 & -0.0052 & 0.0009 & -0.0053 & 0.0009 & -0.0046 & 0.0013 & -0.0052 & 0.0008 \\
Winter & -0.0057 & 0.0013 & -0.0054 & 0.0012 & -0.0058 & 0.0008 & -0.0058 & 0.0010 & No data & No data & No data & No data
\end{tabular}


It is evident that there are also important differences in LRs during the day, with steeper LRs during daytime hours and shallower LRs at night (Fig. 3b), leaving aside the peaks in the morning hours between 07:00 and 10:00 (depending on the season), which are caused by the different timing of the sites' exposure to solar radiation (Petersen and Pellicciotti, 2011; Immerzeel and others, 2014). This pronounced diurnal variability is strong in all seasons except monsoon, where variability is generally smoothed (Kattel and others, 2012). By strongly reducing incoming shortwave radiation, the clouds typical of the monsoon period inhibit the main mechanism of energy transmission, which has a marked diurnal variability. As a result, temperature fluctuations during the day and differences between locations are dampened.

The same analysis was repeated with the seasonal divisions adopted by Steiner and Pellicciotti (2016) and Steiner and others (2015), and no major differences were obtained, so we report here and below only results that refer to the seasonality defined in Table 1.

A main goal of this work was to investigate whether inclusion of measurements at much higher locations would result in different LRs than those obtained only from records in the main valley at medium elevations. To test this hypothesis, we calculate the daily LRs for each season and year using all sensors available. This means that LRs are potentially calculated with a different number of records for each time step (Section 3.1). This reduces comparability (in contrast to the valley subset, where all LRs were calculated based on the same number of sensors), but allows us to determine if LRs are robust independent of the selection of observation locations.

Table 2 shows the average seasonal LRs calculated in this way (under 'Full sensor set'). With few exceptions, LRs are not remarkably distinct from those calculated only with the valley subset (under 'Sensor subset'), suggesting indeed that the LRs derived capture the actual variability of air temperature in the valley. The most prominent differences occur for post-monsoon 2014, where records for the 'Sensor subset' end in mid-October, while later data are available for other sites. Thus, the short record of 'Sensor subset' LRs reflects the monsoon 2014 values, rather than the transitional LR values of post-monsoons 2012 and 2013 and the 'Full sensor set' for post-monsoon 2014.

\subsection{Intra-seasonal variability and lapse rate stability over monsoon}

Figure 4 shows the annual pattern of daily LRs calculated for both the valley subset and the full set of sensors. This figure supports two previous findings: (1) the strong inter-seasonal variability identified by Immerzeel and others (2014) and (2) the LR monsoon lowering observed by Kattel and others (2012). However, it also points to an additional result: that there is also substantial variation within the seasons.

In monsoon, the moisture content reduces the magnitude and variability of LRs (Section 4.1). In pre- and postmonsoon, there is a marked but consistent transition to drier conditions. In winter, on the other hand, very dry conditions alternate with severe storms passing through and depressing the $L R$, which results in the very high spread at the daily scale visible in Figure 4. This is true for all three years and independently of the dataset used to calculate the LRs. This seems to suggest that most monsoon days are similar, and most premonsoon and post-monsoon days are autocorrelated in a nearly linear transition, but winter days vary a lot, as confirmed by the high standard deviation (Table 2).

These results are valid for both measurement set-ups: the valley subset (Fig. 4a) and the full set of all sensors, including the upper valley and higher-elevation sites with shorter record (Fig. 4b). The only difference is that, when we use the valley subset, LRs are more closely clustered at all times, with the same strong seasonal cycle: clustering during the pre-monsoon, monsoon and post-monsoon, but significant scatter during winter.

Figure 5 shows the monsoon LRs for 2012, 2013 and 2014. In 2012, the observations are similar to the set-up analysed by Immerzeel and others (2014), but many more sites were available for the 2013 and 2014 seasons. Despite the differences in the measurement set-ups, two results are apparent: (1) lapse rates are highly linear (i.e. strong regression results), with a very high $R^{2}$ very close to 1 ; and (2) the LRs are very similar (as shown already in Fig. 4), with values of -0.0047 (for 2012), -0.0043 (for 2013) and -0.0048 (for 2014) ${ }^{\circ} \mathrm{C} \mathrm{m}^{-1}$, confirming that the lowering of the LR in monsoon is consistent over the three years and despite the different set-up. The small difference in the values might be associated with real differences in the meteorological characteristics of the three years, but could also be due to the fact that the 2013 and 2014 LRs include observations from higher elevations and from the easternmost section of the valley.

This is an important result, as it suggests that once the appropriate LR is identified for this key season, it could be kept constant for glacio-hydrological modelling. It would be ideal to verify this with further monitoring and at other highelevation sites affected by the monsoon.

\subsection{Local variability observed at transects}

Observations at transects set up across valley to capture local effects were available for three periods (postmonsoon 2012, winter 2012/13 and pre-monsoon 2013; see Section 3.3) and are shown in Figure 6. Colour codes indicate the different transects.

Local variability is evident at the three transects in all three seasons, with very steep local LRs and differences of $>2{ }^{\circ} \mathrm{C}$ for sites located a few tens of meters apart in elevation (Fig. 6). The central location (indicated by suffix c) exhibits the middle temperature in post-monsoon and winter. At the two uppermost sites (transects 7 and 10), the northern $T$-logger is warmer than the southern one in both seasons, likely because of the southern aspect, but the opposite is true for transect 5, where the southern site is warmer. In premonsoon, variability is larger and complex, with larger scatter (and $R^{2}$ calculated from seasonal values equal to 0.77 ) around a $L R$ of $-0.006^{\circ} \mathrm{C} \mathrm{m}^{-1}$ (Fig. 6 right panel).

To explain the lateral temperature variability at the transects, we looked in detail at the time series of daily temperature at each of the transects. Additionally, using the daily LRs derived for each season (Table 2) we model the temperature at each site with the all-sensor observed daily LR to reduce the elevation effect, and then calculate the daily deviation from this value to examine how each site behaves relative to the whole-valley fit. We then use modelled potential incoming shortwave radiation at each site to interpret the discrepancies observed (Section 3.3). Figure 7 shows the time series of observed temperature, deviation from main LR and potential clear-sky solar radiation for transects 5 (Fig. 7a) and 7 (Fig. 7b). Transect 

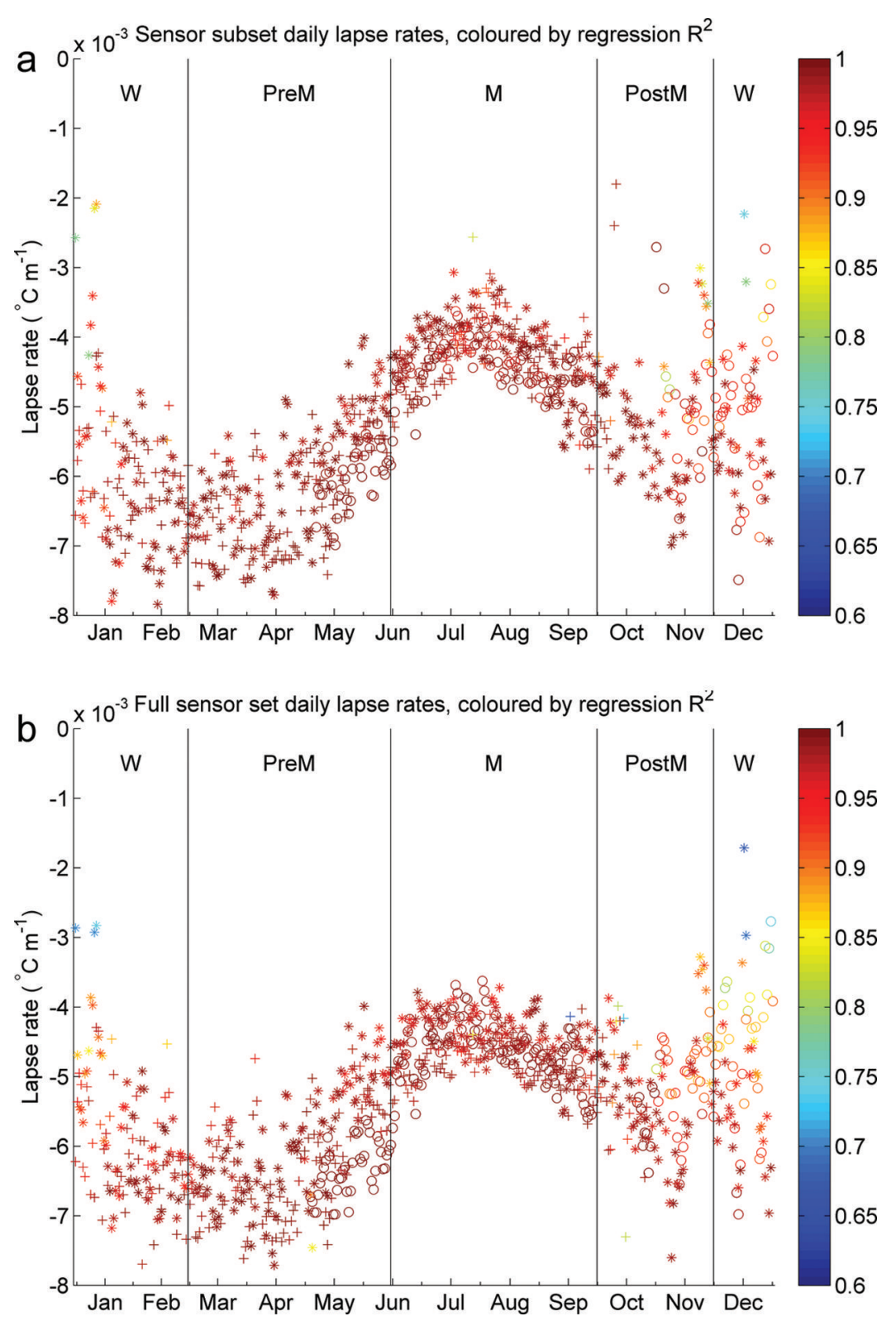

Fig. 4. Daily mean LRs for the period of record for the 'Sensor subset' (a) and the 'Full sensor set' (b). Circles indicate 2012, stars 2013, and asterisks 2014. Regressions have been trimmed to $p<0.1$ and points are coloured by the strength of the regression.

10 behaves in a manner similar to transect 7 and is not reported here for reasons of space.

At transect 5, the southern sensor (with therefore northern aspect) records the highest temperature, followed by the central and then northern sensors (Fig. 7a). This is not intuitive, since we would expect sensors facing north to receive the smallest amount of solar radiation. Deviation from the main LR is stonger in the winter months (Fig. 7a middle panel), with the southern sensor being warmer by a few degrees. This behaviour is explained, however, by the modelled solar radiation, which shows that the southern sensor receives much higher solar irradiance than the other two sites (Fig. 7a bottom panel). This is probably due to local shading effects that overcome the predominant exposure. At the T7 and T10 transects, on the other hand, aspect is the predominant control on the observed variability, and we observe that the northern sensor (T7n, facing south) is the warmest, followed by the central sensor (T7c) and then southern sensor (T7s) (Fig. 7b central and middle panels). Radiation is higher, as expected, at the sensor with the southern exposure (Fig. 7b bottom panel). This effect diminishes as solar angles get higher and more of the valley is illuminated (Fig. $7 \mathrm{~b}$ bottom panel).

In summary, analysis of the transect variability suggests a predominant effect of solar exposure, which generally results in the sensors located on the northern flanks of the valley (southern aspect) having higher temperature than those on the southern slopes. Differences can be high, up to several degrees, and therefore seem important to consider in applications. This effect can be counterbalanced by local shading and other factors that diminish the receipt of solar radiation, as demonstrated by the observations at transect 5 .

The importance of the exposure established here cannot be evaluated in combination with elevation, since the transects were chosen to have very similar elevations. However, based on these results it seems important to evaluate whether this effect (warmer sites on the northern flanks) can counterbalance the LR. For this, transects across valley at high elevations would be necessary (which were 


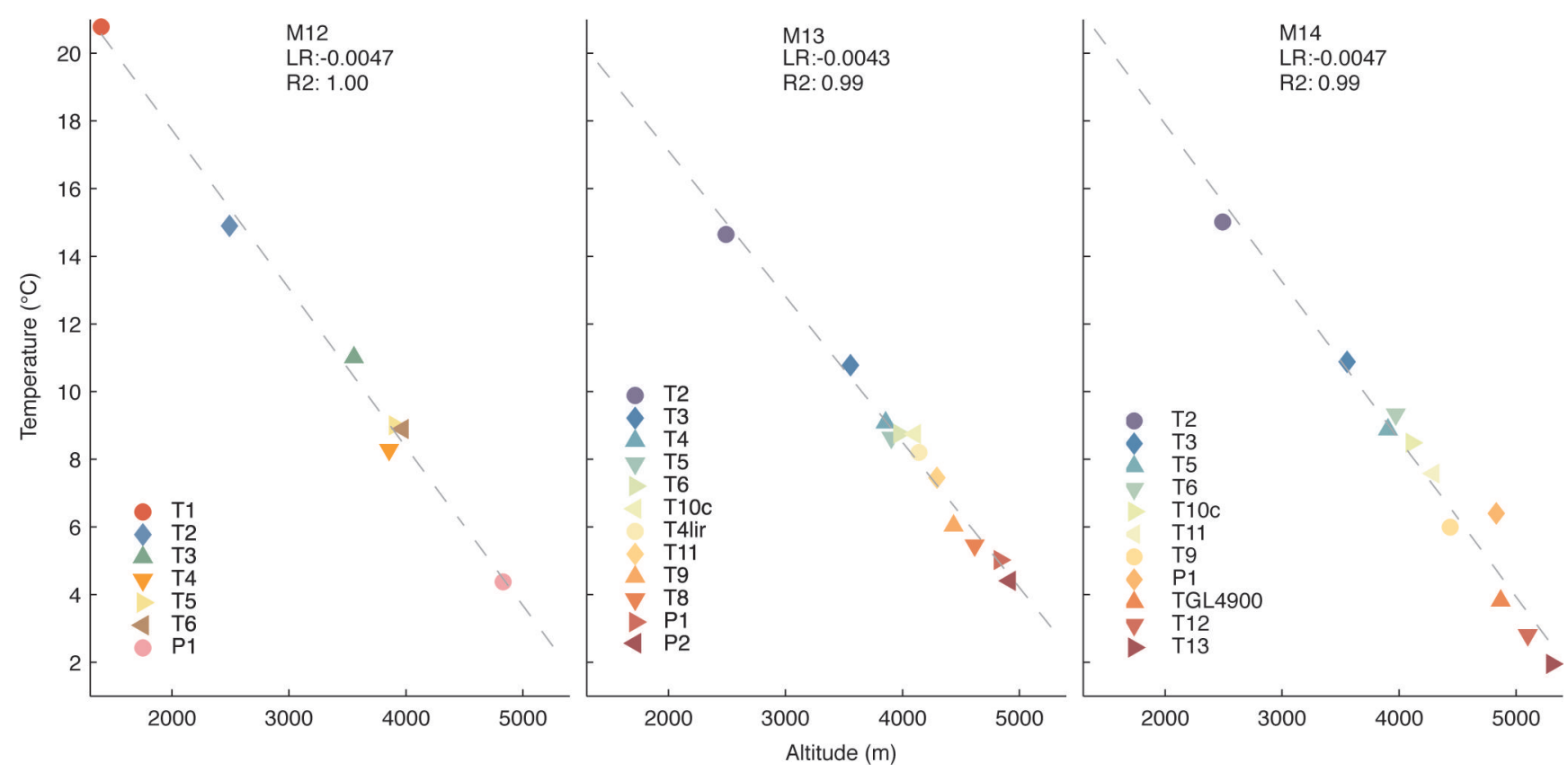

Fig. 5. Temperature versus elevation for the three monsoon seasons 2012 (left), 2013 (centre) and 2014 (right) at all locations available for each season. Also indicated is the LR calculated from the linear regression of seasonal values $\left({ }^{\circ} \mathrm{C} \mathrm{m}^{-1}\right)$ and the correlation coefficient, $R^{2}$.

not available for this study due to logistical constraints) and they seem an important next step of research. While this work has established that along the main valley (including its easternmost sections at high elevations) the LRs are very similar to those calculated from a limited number of sensors in the lower reaches, and elevation is a main control of temperature variability (albeit with values different from the so-called ELR and very strong seasonal and diurnal variability), it also points to the fact that more complex variability can be expected across valley at higher elevations, where the effect of warming on the northern slopes might locally balance the cooling effect due to elevation.
Other sites show a deviation from the main LR: P1 and T8 show lower temperatures, and this might be due to the presence of snow at either or both sites for some time, considering that these are two of the highest sites (Fig. 2). T4Lir, T9 and T11 all exhibit higher temperatures, but the actual causes of this are not known, and their records do not cover the full period of analysis. A possible reason, however, could be their proximity to glacier moraines, which warm up considerably during the day because of solar irradiance, which is highest during the pre-monsoon season (Steiner and others, 2015; Buri and others, 2016). While this seems a plausible explanation, more in-depth

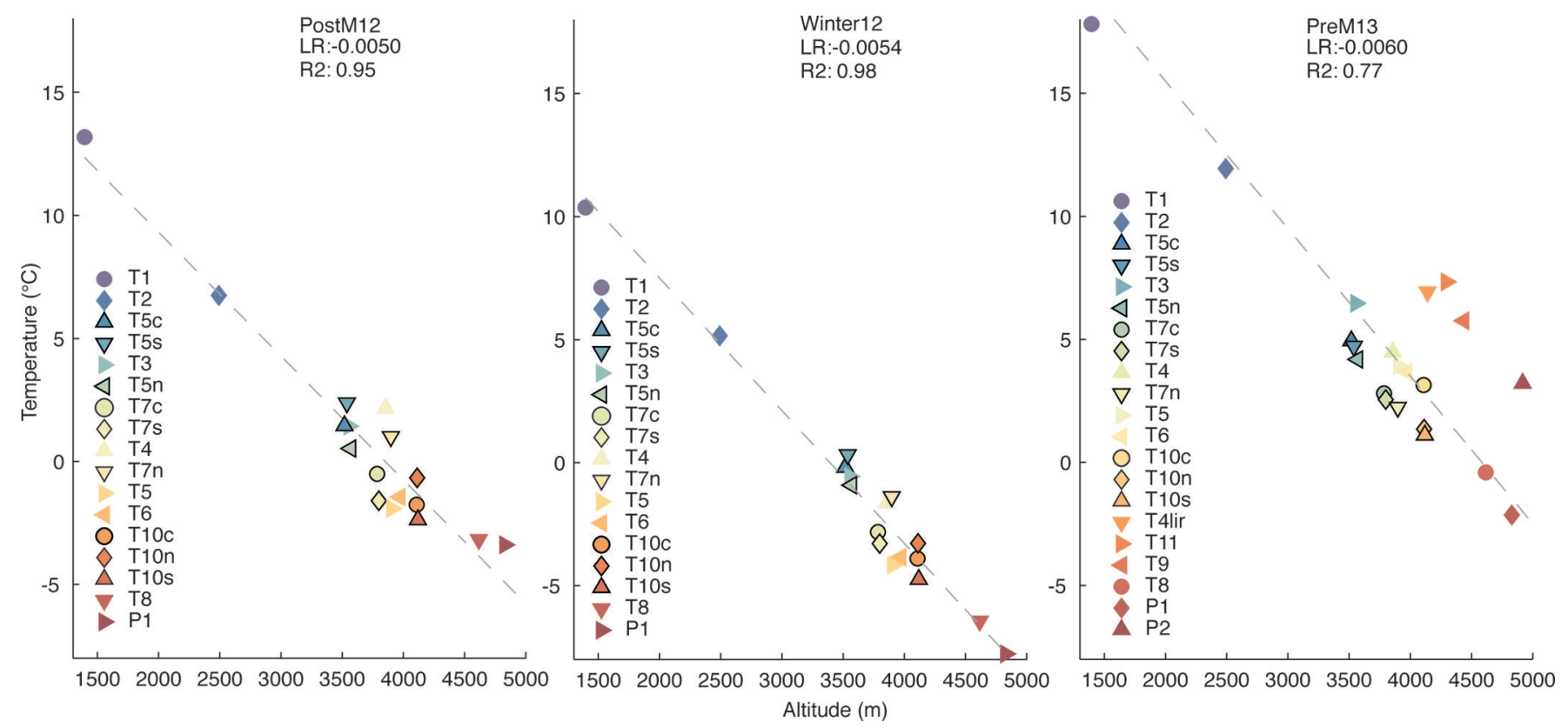

Fig. 6. Temperature versus elevation for the three seasons post-monsoon 2012, winter 2012/13 and pre-monsoon 2013 at all locations available for each season. Also indicated is the LR calculated from the linear regression of daily values $\left({ }^{\circ} \mathrm{Cm}^{-1}\right)$ and the correlation coefficient, $R^{2}$ 

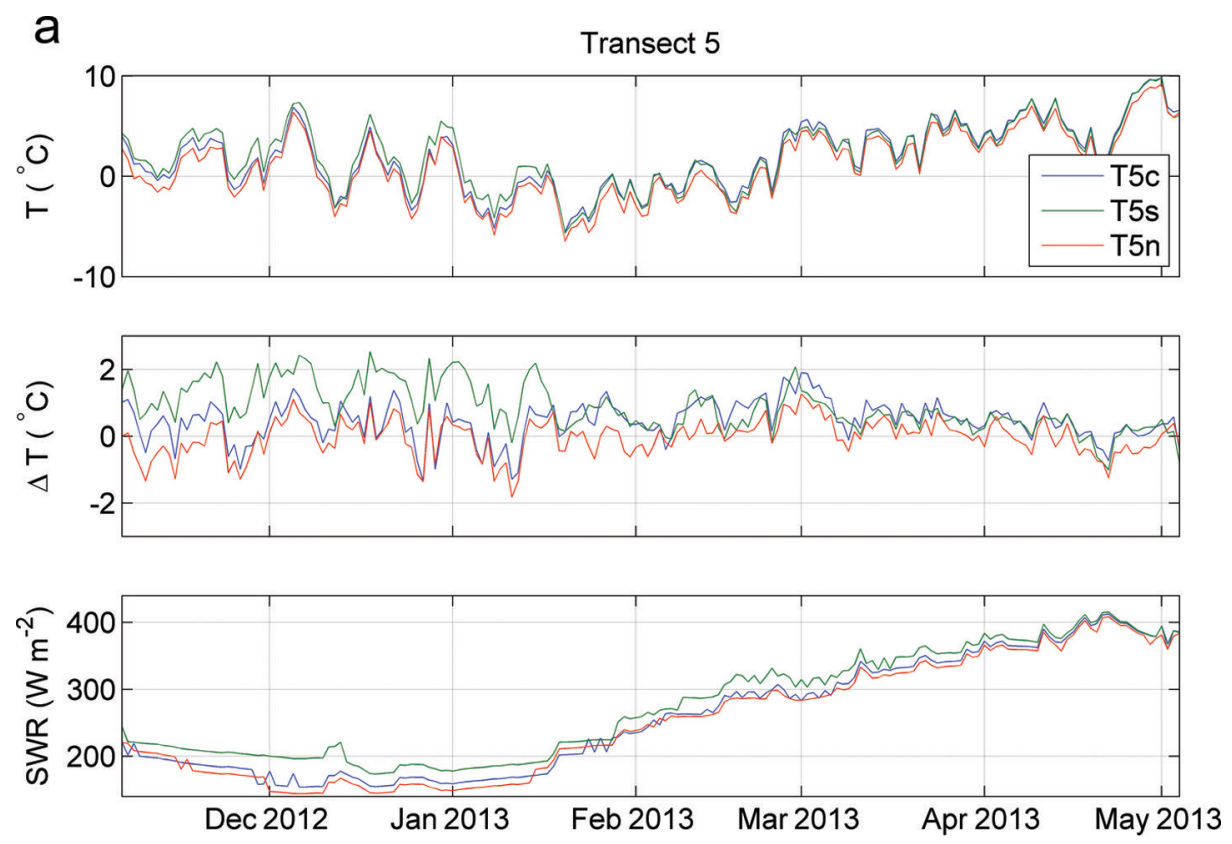

b Transect 7
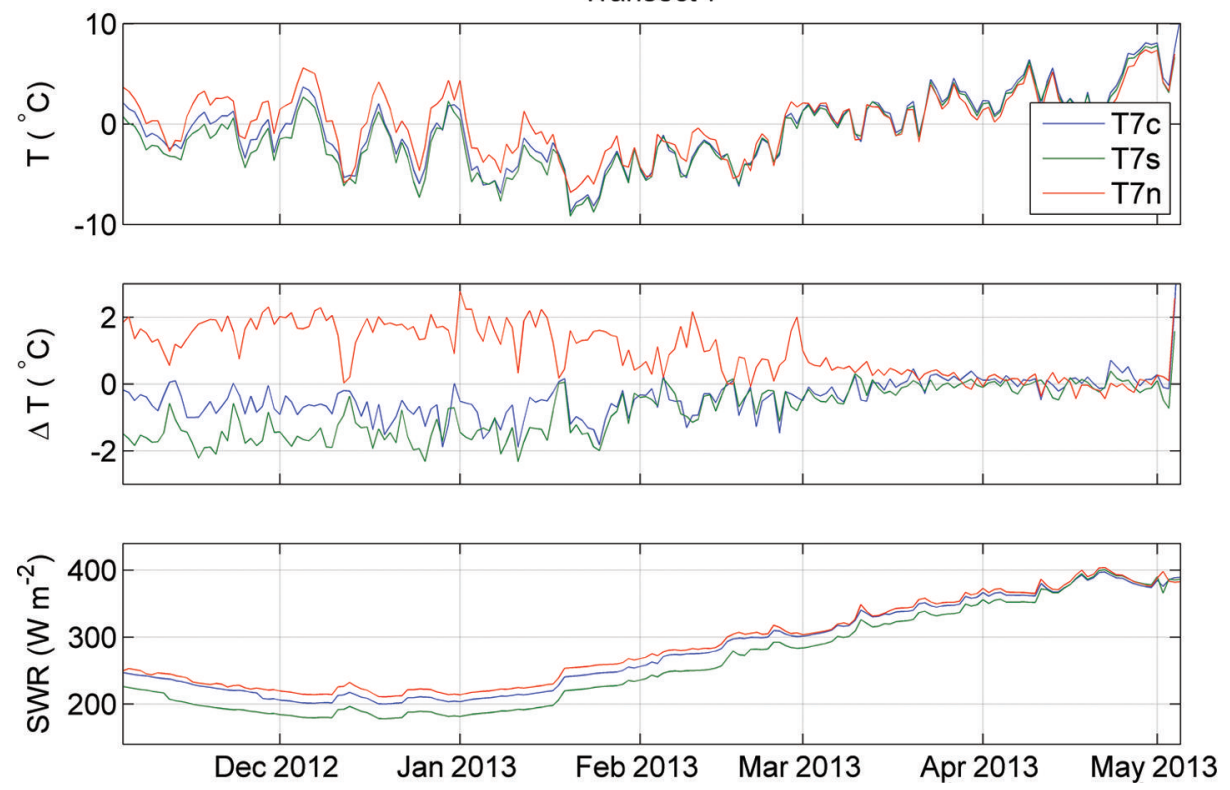

Fig. 7. Observed daily air temperature (top), deviation of observed temperature from that estimated by the daily LR determined from the 'Full sensor set' (middle), and modelled incoming shortwave radiation (bottom) at transect 5 (a) and transect 7 (b); see Figure 1 for location.

analysis should be devoted to understanding these local effects at high elevations. The 'anomalous' warm behaviour of $\mathrm{P} 2$ is probably due to the fact that the period of record in pre-monsoon 2013 is shorter (Fig. 2) and limited to the second part of the pre-monsoon season, when temperatures are higher (i.e. the record is biased towards higher temperatures) and snow, which reduces near-surface temperature and is present for the first part of the pre-monsoon season at these elevations, has likely disappeared.

While solar radiation is a critical driver of local temperature variability, other factors can moderate its influence, each requiring specific, designed further study. This study has not attempted to address the roles of snow, vegetation, wind, or exposure to enhanced longwave radiation, which can normalize or further perturb a site from the large-scale LR.

\subsection{Elevation of the $0^{\circ} \mathrm{C}$ line}

Table 3 shows the elevation of the $0^{\circ} \mathrm{C}$ line calculated using the seasonal and annual LR for 2012 and 2013. Differences when using the seasonal LRs are important in monsoon (in both years), followed by pre-monsoon. In monsoon, using a constant annual LR results in the $0^{\circ} \mathrm{C}$ line being lower by $\sim 300 \mathrm{~m}$ than that obtained applying the seasonal LRs (by $278 \mathrm{~m}$ in 2012 and $355 \mathrm{~m}$ in 2013). In pre-monsoon, by contrast, the annual LR predicts a higher $0^{\circ} \mathrm{C}$ line (by $134 \mathrm{~m}$ in 2012 and $83 \mathrm{~m}$ in 2013), because the pre-monsoon LR is steeper than the average annual one. There is little or no effect on the winter and post-monsoon $0^{\circ} \mathrm{C}$ line, since the corresponding seasonal LRs are very similar to the annual ones. However, the effect is important in the two seasons, pre-monsoon and monsoon, when melt is highest (Ragettli and others, 2015; Steiner and others, 2015; Buri and others, 
2016), and in the main rainfall season (monsoon), so it seems important to use seasonal LRs in hydrological and mass-balance models simulating melt and snowfalls.

\section{CONCLUSIONS}

Near-surface air temperature at high elevations is considerably different from that of the free atmosphere at the same elevation, although they are often treated the same in hydrological modelling studies of high-elevation catchments. This difference (Richner and Phillips, 1984; Pepin and Losleben, 2002) has only recently found place in our understanding of the meteorology and climate of highelevation catchments as applied to hydrological and glaciological modelling (Kattel and others, 2012; Thayyen and Dimri, 2014; Ayala and others, 2015). Indeed, many hydrological impact studies have used LRs derived from assumptions of free-atmosphere behaviour. Increasingly, however, efforts in the glaciological and hydrological community have pointed to the importance of surface processes in determining the actual rate at which air temperature varies in high-elevation catchments (Minder and others, 2010; Petersen and Pellicciotti, 2011; Thayyen and Dimri, 2014).

In this study, we analysed 2.75 years of air temperature data collected at a network of up to 27 locations recording sub-hourly temperature in the Langtang River catchment. The highest sensor was installed at $\sim 5300 \mathrm{~m}$ a.s.l. and the set-up covers the entire valley up to Langtang Glacier, the largest and easternmost glacier in the catchment. This is a unique dataset that we used to test assumptions about the decrease of air temperature with elevation, and in particular the commonly assumed value of $0.0065^{\circ} \mathrm{C} \mathrm{m}^{-1}$; to analyse the LRs' seasonality; and to test if LRs are stable over multiple years.

Our main conclusions are as follows:

1. LRs in the Langtang valley are well defined, indicating a dependence of near-surface air temperature on elevation that has a marked seasonality in both magnitude and variability but is consistent interannually. In monsoon, LRs are much shallower, a fact that had been observed previously and that seems attributable to the monsoon reducing the temporal and spatial variations of air temperature, partly through the release of latent heat to the atmosphere at high elevations. The steepest LRs are in the pre-monsoon season, when incoming solar radiation is a key control on energy exchanges, while the most variable LRs occur in winter due to dynamic weather patterns.

2. Local variability inferred from transects across valley with sensors at similar elevation can be high (with mean differences up to $2^{\circ} \mathrm{C}$ ), and we show that this is mainly related to aspect due to its control on solar radiation receipts, with south-facing sensors showing higher temperatures. The strong warming effect on south-facing slopes can be locally counteracted by local effects such as topographic shading, so that at our lowest transect the north-facing slopes received more radiation than the shaded south-facing sites. When considering the entire network, LRs become weaker (i.e. the strength of the regression decreases) in the pre-monsoon season, with differences at single sites with respect to the average linear decrease with elevation. In this season, some of
Table 3. Elevation of the $0^{\circ} \mathrm{C}$ line obtained by extrapolating air temperature from Kyanjing station using the calculated seasonal LRs (from Table 2) or the mean annual LR for the corresponding year. Diff. indicates the difference with respect to the $0^{\circ} \mathrm{C}$ line calculated with the seasonal LR, assumed to be the more accurate approach

\begin{tabular}{lcccc}
\hline & & Seasonal LR & Annual LR & Diff. \\
& & m a.s.I. & ma.s.l. & m \\
\hline \multirow{2}{*}{2012} & & & \\
& & & & \\
& PreM & 4633 & 4766 & -134 \\
& PostM & 5850 & 5572 & 278 \\
& Winter & 3914 & 3914 & 13 \\
& PreM & 4571 & 4654 & -83 \\
& M & 5862 & 5507 & 355 \\
& PostM & 4498 & 4487 & 11 \\
& Winter & 3495 & 3467 & 28 \\
\hline
\end{tabular}

the sites in the northern and eastern sections seem to be warmer, likely because of a combination of aspect and proximity to large moraines. In monsoon, however, LRs are strongly linear for both the sensor subset and full set. This suggests that use of a uniform LR is justified in the monsoon season, while more analysis should be carried out to shed light on the mechanisms controlling premonsoon temperature, when transition effects are important (e.g. snow and changes in weather).

3. Use of seasonal LRs seems imperative given the effect that they have on the elevation of the $0^{\circ} \mathrm{C}$ line, with especially marked differences of up to several hundred metres when constant LRs are used in pre-monsoon and monsoon (the key seasons for melt and snowfall simulations). Since the $0^{\circ} \mathrm{C}$ threshold is an important control of melt and of the phase of the precipitation, this seems an important recommendation for modelling studies. However, use of a specific seasonal LR or of an average seasonal value does not have a major impact, so that once the correct LR value for a specific season is identified, it could be maintained constant.

\section{ACKNOWLEDGEMENTS}

We thank the numerous people that joined the fieldwork and helped to collect data in the field, especially Lene Petersen and Tek Rai. We also thank ICIMOD for general support of our research activities. This study was partially funded by the US Agency for International Development (USAID) High Mountain Glacier Watershed Program Climber-Scientist (grant No. CCRDCS0010), which is warmly acknowledged for its constant, valuable support, and by the Swiss National Science Foundation (SNF) project UNCOMUN (Understanding Contrasts in High Mountain Hydrology in Asia). We also thank Fionna Heuff for preprocessing the 2014 data. The comments of two anonymous reviewers and Scientific Editor Lindsey Nicholson helped considerably to improve the manuscript. Finally, we thank the people of the Langtang and Kyanjing villages who welcomed us into their homes and valley over the course of several field seasons, and many of whose homes no longer exist. 


\section{REFERENCES}

Ayala A, Pellicciotti F and Shea J (2015) A new model of air temperature over melting glaciers: common patterns revealed by observations on three alpine glaciers. J. Geophys. Res., 120, 3139-3157 (doi: 10.1002/2015JD023137)

Blandford TR, Humes KS, Harshburger BJ, Moore BC and Walden VP (2008) Seasonal and synoptic variations in near-surface air temperatures in a mountainous basin. J. Appl. Meteorol. Climatol., 47, 249-261 (doi: 10.1175/2007JAMC1565.1)

Buri P, Pellicciotti F, Steiner J, Miles E, Reid T and Immerzeel W (2016) A grid-based model of backwasting of supraglacial ice cliffs over debris-covered glaciers. Ann. Glaciol. (doi: 10.3189/ 2016AoG71A059) (see paper in this issue)

Fujita K and Sakai A (2000) Air temperature environment on the debris-covered area of Lirung Glacier, Langtang Valley, Nepal Himalayas. IAHS Publ. 264 (Workshop at Seattle 2000 - DebrisCovered Glaciers), 83-88

Gardner AS and 7 others (2009) Near-surface temperature lapse rates over arctic glaciers and their implications for temperature downscaling. J. Climate, 22, 4281-4298 (doi: 10.1175/ 2009JCLI2845.1)

Greuell W and Böhm R (1998) 2 m temperatures along melting midlatitude glaciers, and implications for the sensitivity of the mass balance to variations in temperature. J. Glaciol., 44(146), 9-20

Immerzeel W, Petersen L, Ragettli S and Pellicciotti F (2014) The importance of observed gradients of air temperature and precipitation for modeling runoff from a glacierised watershed in the Nepalese Himalayas. Water Resour. Res., 50(3), 2212-2226 (doi: 10.1002/2013WR014506)

Iqbal M (1983) An introduction to solar radiation. Academic Press, London

Kattel D, Yao T, Yang K, Tian L, Yang G and Joswiak D (2012) Temperature lapse rate in complex mountain terrain on the southern slope of the central Himalayas. Theor. Appl. Climatol., 113(3-4), 671-682 (doi: 10.1007/s00704-012-0816-6)

Lundquist J, Pepin N and Rochoford C (2008) Automated a Igorithm for mapping regions of cold air pooling in complex terrain. J. Geophys. Res., 113(D22), D22107 (doi: 10.1029/ 2008JD009879)

Marshall SJ and Sharp MJ (2008) Temperature and melt modeling on the Prince of Wales ice field, Canadian High Arctic. J. Climate, 22, 1454-1468 (doi: 10.1175/2008JCLI2560.1)

Marshall SJ, Sharp MJ, Burgess DO and Anslow FS (2007) Nearsurface-temperature lapse rates on the Prince of Wales icefield, Ellesmere Island, Canada: implications for regional downscaling of temperature. Int. J. Climatol., 27, 385-398 (doi: 10.1002/ joc.1396)

Miles E, Pellicciotti F, Willis I, Steiner J, Buri P and Arnold N (2016) Refined energy-balance modelling of a supraglacial pond,
Langtang Khola, Nepal. Ann. Glaciol., 57(71), 29-40 (doi: $10.3189 / 2016$ AoG71A421) (see paper in this issue)

Minder JR, Mote P and Lundquist J (2010) Surface temperature lapse rates over complex terrain: lessons from the Cascade Mountains. J. Geophys. Res., 115(D14), D14122 (doi: 10.1029/ 2009JD013493)

Pellicciotti F, Raschle T, Huerlimann T, Carenzo M and Burlando P (2011) Transmission of solar radiation through clouds on melting glaciers: a comparison of parameterizations and their impact on melt modelling. J. Glaciol., 57(202), 367-381 (doi: 10.3189/002214311796406013)

Pepin N (2001) Lapse rate changes in Northern England. Theor. Appl. Climatol., 68(1-2), 1-16 (doi: 10.1007/s007040170049)

Pepin N and Losleben M (2002) Climate change in the Colorado Rocky Mountains: free air versus surface temperature trends. Int. J. Climatol., 22, 311-329 (doi: 10.1002/joc.740)

Petersen L and Pellicciotti F (2011) Spatial and temporal variability of air temperature on melting glaciers: a comparison of different extrapolation methods and their effect on melt modelling, Juncal Norte Glacier, Chile. J. Geophys. Res., 116(D23), D23109 (doi: 10.1029/2011JD015842)

Petersen L, Pellicciotti F, Juszak I, Carenzo M and Brock B (2013) Suitability of a constant air temperature lapse rate over an alpine glacier: testing the Greuell and Böhm model as an alternative. Ann. Glaciol., 54(63), 120-130 (doi: 10.3189/ 2013AoG63A477)

Ragettli S and 9 others (2015) Unraveling the hydrology of a Himalayan watershed through systematic integration of high resolution in-situ ground data and remote sensing with an advanced simulation model. Adv. Wat. Resour., 78, 94-111 (doi: 10.1016/j.advwatres.2015.01.013)

Richner H and Phillips P (1984) A comparison of temperatures from mountaintops and the free atmosphere - their diurnal variation and mean difference. Mon. Weather Rev., 112(7), $1328-1340$

Rolland C (2002) Spatial and seasonal variations of air temperature lapse rates in Alpine regions. J. Climate, 16(7), 1032-1046 (doi: 10.1175/1520-0442(2003)016<3C1032:SASVOA >3E2.0.CO;2)

Steiner J and Pellicciotti $F$ (2016) On the variability of air temperature over a debris-covered glacier, Nepalese Himalaya. Ann. Glaciol., 57(71), (doi: 10.3189/2016AoG71A066) (see paper in this issue)

Steiner J, Pellicciotti F, Buri P, Miles E, Reid T and Immerzeel W (2015) Modeling ice-cliff backwasting on a debris-covered glacier in the Nepalese Himalaya. J. Glaciol. 61(229), 889-907 (doi: 10.3189/2015JoG14J194)

Thayyen R and Dimri A (2014) Factors controlling slope environmental lapse rate (SELR) of temperature in monsoon and coldarid glacio-hydrological regimes of the Himalaya. Cryosphere Discuss., 8, 5645-5686 (doi: 10.5194/tcd-8-5645-2014) 